\title{
Caracterização nutricional das folhas de Moringa oleifera (MOL) para frangos de corte
}

\author{
[Chemical and nutritional characterization of moringa oleifera leaves for broilers] \\ G.M. Macambira ${ }^{1}$, C.B.V. Rabello', M.I.V. Navarro ${ }^{2}$, M.C.M.M. Ludke ${ }^{1}$, J.C.R. Silva ${ }^{1}$, E.C. Lopes ${ }^{1}$, \\ G. R. Nascimento ${ }^{1}$, C.C. Lopes $^{3}$, J.M. Bandeira ${ }^{1}$, D.A. Silva ${ }^{1}$ \\ ${ }^{1}$ Universidade Federal Rural de Pernambuco - Recife, PE \\ ${ }^{2}$ Instituto de Ciência Animal de Cuba - ICA - San José de Las Lajas, Mayabeque, Cuba \\ ${ }^{3}$ Universidade Federal do Amazonas - Instituto de Ciências Sociais, Educação e Zootecnia - Parintins, AM
}

\section{RESUMO}

Objetivou-se determinar os valores energéticos e nutricionais das folhas de Moringa oleifera (MOL) para frangos de corte. Utilizaram-se 90 pintos machos, Cobb-500, com 14 dias de idade, distribuídos em delineamento inteiramente ao acaso, com cinco tratamentos e seis repetições de três aves. Os tratamentos consistiram de: uma dieta referência e quatro dietas com substituição de $10 \%, 20 \%, 30 \%$ e $40 \%$ da dieta referência pelas folhas de MOL. O período experimental teve duração de oito dias, utilizando-se a metodologia de coleta total de excretas. Foram determinados os valores de energia metabolizável aparente (EMA), aparente corrigida para o nitrogênio (EMAn), coeficiente de metabolizabilidade aparente da matéria seca (CMAMS), da proteína bruta (CMAPB) e da energia bruta (CMAEB). Os resultados obtidos foram submetidos à análise de variância e à análise de regressão a $5 \%$ de probabilidade. Houve efeito quadrático das variáveis à medida que a moringa era adicionada à ração referência. Na derivação das equações de regressão, o nível que proporcionou os melhores valores de EMA, EMAn e CMEB foi de $37,7 \%$ de substituição. O farelo de folhas MOL apresentou médias de $3140 \mathrm{kcal} / \mathrm{kg}$ de EMA, $2845 \mathrm{kcal} / \mathrm{kg}$ de EMAn, 76,92\% de CMAEB, 76,63\% de CMAMS e 73,42\% de CMAPB.

Palavras-chave: alimento alternativo, digestibilidade, energia metabolizável, fibras

\begin{abstract}
This study aimed to determine the energy and nutritional value of the leaves of Moringa oleifera (MOL) for broilers. We used 90 male chicks, Cobb-500, with 14 days of age in a completely randomized design with five treatments and six repetitions of three birds. The treatments were: reference diet and 4 diets with substitution of $10 \%, 20 \%, 30 \%$, and $40 \%$ of the diet by reference sheet MOL. The trial lasted eight days, using the method of total excreta collection. The apparent metabolizable energy (AME), apparent corrected for nitrogen (AMEn), apparent metabolizable coefficient of dry matter (AMCDM), crude protein (AMCCP) and gross energy (AMCGE). The results were submitted to analysis of variance and regression analysis at 5\% probability. There was a quadratic effect of the variables as the moringa was added to the reference diet. In the derivation of the regression equations the level that provided the best values of AME, AMEn, AMCGE was $37.7 \%$ substitution. The leaves meal MOL presented average $3140 \mathrm{kcal} / \mathrm{kg}$ of AME, 2845kcal / kg AMEn, 76.92\% of AMCGE, 76.63\% of AMCDM and 73.42\% of AMCCP.
\end{abstract}

Keywords: alternative food, digestibility, metabolizable energy, fibers

Recebido em 2 de janeiro de 2017

Aceito em 18 de abril de 2017

E-mail: gabriel.m.y@hotmail.com 


\section{INTRODUÇÃO}

A alimentação, como um pilar básico para a produção animal, representa o maior custo de produção no setor avícola, estando em torno de 60 a 70\%. Levando isso em consideração, a qualidade dos ingredientes utilizados é de extrema importância para se alcançarem índices zootécnicos satisfatórios. Segundo Ribeiro et al. (2010), a grande variação de preço do milho e do farelo de soja, principais ingredientes que compõem as rações, leva os pesquisadores a se lançarem em busca de alimentos ditos alternativos que visem à diminuição dos custos de produção, atrelados ao não comprometimento do desempenho dos animais.

Nesse contexto, as folhas da Moringa oleifera estão sendo amplamente estudadas, visto que possuem grande potencial nutricional (Nkakwana et al., 2014). O teor proteico de suas folhas pode variar de 17 a $32 \%$, sendo ricas em aminoácidos essenciais (Makkar e Becker, 1997; Moura et al., 2010; Moyo et al., 2011). Além dos altos teores de proteína, as folhas ainda apresentam conteúdo significativo de fibra, compostos antioxidantes, tais como polifenóis e vitaminas, sendo também ricas em carotenoides e cálcio (Nkakwana et al., 2014).

Por sua vez o conhecimento do valor energético dos alimentos é de extrema importância para as formulações de rações que visem ao ótimo desempenho dos animais (Sakomura e Rostagno, 2007). Existem na literatura trabalhos em que são citados os valores de energia metabolizável para a Moringa oleifera, no entanto os autores não apresentam as metodologias utilizadas para a determinação de tais valores (Olugbemi et al., 2010; Nkakwana et al., 2014). Já outros trabalhos determinaram a energia metabolizável (EM) por métodos indiretos utilizando equações de predição (Ayssiwede et al., 2011; Kaijage et al., 2015).

Com base no exposto, objetivou-se com essa pesquisa determinar a composição bromatológica, assim como os valores energéticos das folhas de Moringa oleifera para frangos de corte, bem como os efeitos de sua substituição sobre a digestibilidade dos nutrientes.

\section{MATERIAL E MÉTODOS}

O experimento foi aprovado pelo Comitê de Ética e Uso de Animais (Ceua) da Universidade Federal Rural de Pernambuco, com número de protocolo: 23082.000497/2015.

Folhas frescas de Moringa oleifera de plantas cultivadas na cidade de Caraúbas, Rio Grande do Norte, foram utilizadas neste experimento. O material foi seco ao sol, moído, e amostras foram enviadas ao laboratório de Nutrição Animal (LNA) do Departamento de Zootecnia da Universidade Federal Rural de Pernambuco (UFRPE), para que fossem realizadas análises bromatológicas e obtidos os teores de energia bruta, proteína bruta, extrato etéreo, fibra em detergente neutro, fibra em detergente ácido e cinzas, de acordo com as metodologias descritas por Silva e Queiroz (2002). Foram realizadas, também, análises de aminoácidos pelo método de hidrólise proteica, seguida de leitura em cromatografia líquida de alto desempenho (HPLC) pela empresa Evonik.

O experimento de metabolismo foi executado no Laboratório de digestibilidade de não ruminantes, no Departamento de Zootecnia da Universidade Federal Rural de Pernambuco. Noventa pintos machos da linhagem Cobb 500, com idade de 14 dias e peso médio de $460 \mathrm{~g}$, foram selecionados e transferidos para gaiolas metabólicas com dimensões de $1,00 \times 0,50 \times$ $0,50 \mathrm{~m}$, dotadas de comedouros tipo calha, bebedouros tipo copo e bandejas coletoras de excretas. Os animais foram distribuídos em um delineamento inteiramente causalizado, com cinco tratamentos, seis repetições de três aves por unidade experimental. Dados de temperatura e umidade relativa do ar foram coletados durante todo o período experimental.

Os tratamentos consistiam de uma ração referência, formulada para atender as necessidades nutricionais dos frangos de corte segundo as tabelas de Rostagno et al. (2011), assim como quatro rações testes, em que o farelo de folhas substituía, com base na matéria natural, $10 \%, 20 \%, 30 \%$ e $40 \%$ da ração referência. A Tab. 1 mostra a composição nutricional da ração referência. 
Tabela 1. Composição percentual e valor nutricional da dieta referência

\begin{tabular}{lrll}
\hline Ingredientes & \multicolumn{2}{c}{ Composição Nutricional } & 3,100 \\
Milho & 55,550 & Energia metabolizável (kcal/kg) & 21,2 \\
Farelo de soja & 36,231 & Proteína bruta (\%) & 3,88 \\
Óleo de Soja & 4,310 & Fibra em detergente neutro (\%) & 1,79 \\
Calcário & 1,086 & Fibra em detergente ácido (\%) & 6,91 \\
F. Bicálcico & 1,539 & Extrato etéreo (\%) & 0,841 \\
Sal comum & 0,419 & Cálcio (\%) & 0,210 \\
DL-Metionina 99\% & 0,308 & Sódio (\%) & 0,585 \\
L-Lisina HCl 78,8\% & 0,231 & Potássio (\%) & 0,401 \\
L-Treonina 98,5\% & 0,074 & Fósforo disponível (\%) \\
Bacitracina de Zinco 15\% & 0,050 & Lisina digestível (\%) & 1,217 \\
Salinomicina 12\% & 0,050 & Metionina digestível (\%) & 0,588 \\
Premix Vitamínico & & 0,791 \\
Premix Mineral $^{2}$ & 0,100 & Treonina digestível (\%) & 0,238 \\
\hline
\end{tabular}

${ }^{\mathrm{I}}$ Níveis de garantia do premix vitamínico: vitamina A (min): 9.000.000UI $/ \mathrm{kg}$, vitamina D3 (min): 1.600.000UI/kg, vitamina E (min): $14.000 \mathrm{UI} / \mathrm{kg}$, vitamina K3 $(\mathrm{min}) 1.500 \mathrm{mg} / \mathrm{kg}$, vitamina B1 (min): $1.000 \mathrm{mg} / \mathrm{kg}$, vitamina B2 (min): $4.000 \mathrm{mg} / \mathrm{kg}$, vitamina B6 (min): $1.800 \mathrm{mg} / \mathrm{kg}$, vitamina B $12(\mathrm{~min}): 12.000 \mathrm{mcg} / \mathrm{kg}$, ácido fólico (min): $300 \mathrm{mg} / \mathrm{kg}$, ácido pantotênico (min): $8.280 \mathrm{mg} / \mathrm{kg}$, biotina (min): $50 \mathrm{mg} / \mathrm{kg}$, niacina (min): $30 \mathrm{~g} / \mathrm{kg}$, selênio (min): $250 \mathrm{mg} / \mathrm{kg}$.

${ }^{2}$ Níveis de garantia do premix mineral: ferro $(\mathrm{min}): 60 \mathrm{~g} / \mathrm{kg}$, cobre $(\mathrm{min}): 18 \mathrm{~g} / \mathrm{kg}$, manganês (min): $120 \mathrm{~g} / \mathrm{kg}$, zinco (min): $120 \mathrm{~g} / \mathrm{kg}$ e iodo (min): $2.000 \mathrm{mg} / \mathrm{kg}$.

O ensaio foi realizado no período de 14 a 22 dias de idade das aves, tendo, com isso, duração de oito dias, divididos em quatro de adaptação dos animais às rações e às gaiolas de metabolismo, seguidos de quatro dias de coleta total de excretas. Com o intuito de marcar o início e o final do período de coleta foi adicionado o marcador fecal óxido férrico ao nível de $2 \%$ às rações experimentais, de modo que as excretas marcadas no primeiro dia de coleta e as não marcadas no último não fossem desprezadas. Ração e água foram fornecidas à vontade durante todo o período.

Diariamente, as sobras de ração foram pesadas com o objetivo de se fazer o controle do consumo. As excretas foram coletadas uma vez ao dia, pela manhã, armazenadas em sacos plásticos previamente identificados, pesadas e acondicionadas em freezer para evitar fermentação e, consequentemente, perdas de nutrientes. Amostras de ração também foram armazenadas para posteriores análise.

Ao término do experimento, as amostras de excretas foram descongeladas, homogeneizadas, pré-secas em estufa de circulação forçada de ar à temperatura de $65^{\circ} \mathrm{C}$ por 72 horas, moídas e encaminhadas ao Laboratório de Nutrição Animal da UFRPE. Foram analisados os teores de matéria seca, energia bruta e nitrogênio de acordo com a metodologia descrita por Silva e
Queiroz (2002). A determinação da energia bruta foi realizada em bomba calorimétrica. Amostras das rações também foram encaminhadas ao laboratório para análises.

Com base nos dados de consumo de ração, produção de excretas, matéria seca, energia bruta e nitrogênio, foram calculadas a energia metabolizável aparente (EMA) e a energia metabolizável aparente corrigida para o balanço de nitrogênio (EMAn) segundo equações propostas por Mattenson et al. (1965).

Os coeficientes de metabolizabilidade da energia bruta (CMAEB) também foram calculados. Considerando-se o consumo de matéria seca e o consumo de moringa das unidades experimentais, os valores de EMA e EMAn foram corrigidos pelo consumo do ingrediente sob restrição do intercepto igual a zero, de acordo com recomendação de Pasquetti et al. (2014). Os dados obtidos foram submetidos à análise de variância e de regressão, considerando-se uma probabilidade de $5 \%$.

\section{RESULTADOS}

As médias de temperatura e umidade relativa, durante o experimento, foram de $26,5^{\circ} \mathrm{C}$ e $70,1 \%$, respectivamente. As composições bromatológica, energética e aminoacídica do farelo de folhas de 
Moringa oleifera utilizada neste experimento encontram-se na Tab. 2.

Os valores médios estimados de energia metabolizável aparente, aparente corrigida pelo balanço de nitrogênio e os coeficientes de metabolizabilidade aparente da energia bruta do farelo de folhas de Moringa oleifera são apresentados na Tab. 3 .

Tabela 2. Composição química do farelo de folhas de Moringa oleifera determinada e sua comparação com o farelo de trigo, alimento de perfil nutricional similar (matéria natural)

\begin{tabular}{ccc}
\hline Itens & Moringa oleifera & Farelo de trigo $^{1}$ \\
Composição química e energética & 90,17 & 88,38 \\
Matéria seca (MS) \% & 18,31 & 15,62 \\
Proteína bruta (PB) \% & 41,99 & 40,10 \\
Fibra em detergente neutro (FDN) \% & 23,46 & 13,60 \\
Fibra em detergente ácido (FDA) \% & 11,18 & 4,70 \\
Matéria mineral (MM) \% & 8,65 & 3,50 \\
Extrato etéreo (EE) \% & 4529 & 3914 \\
Energia bruta (EB) kcal/kg & 0,306 & 0,240 \\
Metionina & 0,213 & - \\
Cistina & 0,518 & 0,580 \\
Metionina + cistina & 0,930 & 0,620 \\
Lisina & 0,769 & 0,510 \\
Treonina & 0,366 & 0,240 \\
Triptofano & 0,989 & 1,050 \\
Arginina & 0,769 & 0,500 \\
Isoleucina & 1,491 & 0,950 \\
Leucina & 0,965 & 0,720 \\
Valina & 0,377 & 0,430 \\
Histidina & 0,934 & 0,600 \\
Fenilalanina & 0,894 & - \\
Glicina & 0,739 & - \\
Serina & 0,857 & - \\
Prolina & 1,084 & - \\
Alanina & 1,528 & - \\
Ácido aspártico & 2,025 & - \\
Ácido glutâmico & 1,596 & 1,390 \\
Glicina + serina & & \\
\hline para & & \\
\hline
\end{tabular}

${ }^{1}$ Tabelas Brasileiras para Aves e Suínos (2011).

Foi encontrada diferença significativa para todos os parâmetros analisados. Houve efeito quadrático das variáveis à medida que a moringa era adicionada à ração referência. Na derivação da equação de regressão, o nível de inclusão que resultaria no maior valor de energia metabolizável aparente foi o de $37,7 \%$.

Quanto à EMAn, pode-se observar um aumento nos valores à medida que se aumentaram os níveis de substituição da ração referência pelo ingrediente. Entre os níveis de 10 e $40 \%$, foi encontrado um aumento para essa variável de $1130 \mathrm{kcal} / \mathrm{kg}$. Ao se estabelecer uma comparação entre eles, verificou-se um incremento de $661 \mathrm{kcal}$ de EMAn entre os níveis de 10 e $20 \%$, sendo esta a maior diferença encontrada. $\mathrm{O}$ valor estimado da EMAn para frangos de corte foi de 2840kcal/kg na MS (Fig. 1).

Pode ser observado pelo gráfico que o aumento na substituição das folhas de MOL proporcionou uma diminuição na variabilidade dos valores de EMAn entre as repetições. Esse fato pode ser comprovado observando-se a distribuição dos pontos sobre a reta, em que os níveis de 30 e $40 \%$ proporcionaram menores variações aos valores de EMAn encontrados. O gráfico demonstra que os níveis de $30 \%$ e $40 \%$ foram mais precisos para determinação dos valores energéticos da moringa. 
Foi encontrada diferença significativa entre os valores de EMAn nos diferentes níveis de inclusão. $\mathrm{Na}$ derivação da equação de regressão, foi observado que o nível de inclusão de 37,7\% resultaria no melhor valor e EMAn da MOL. Observando-se a soma dos quadrados dos desvios da EMAn, percebe-se que, com o aumento dos níveis de inclusão, foi havendo uma tendência de diminuição da variabilidade na determinação de tais valores, acontecendo o inverso para níveis menores. Esse fato também pode ser comprovado observando-se a Fig. 1.

Tabela 3. Valores médios da energia metabolizável aparente (EMA), aparente corrigida pelo balanço de nitrogênio (EMAn), coeficiente de metabolizabilidade da energia bruta (CMAEB), matéria seca (CMAMS) e proteína bruta (CMAPB) do farelo de folhas de Moringa oleifera

\begin{tabular}{|c|c|c|c|c|c|c|c|}
\hline \multirow{2}{*}{ Variáveis } & \multicolumn{4}{|c|}{ Níveis de substituição da moringa } & \multirow{2}{*}{$\mathrm{CV}$} & \multirow{2}{*}{$\mathrm{P}$} & \multirow{2}{*}{$\mathrm{Eq}$} \\
\hline & 10 & 20 & 30 & 40 & & & \\
\hline CMEB & $60,7 \pm 5,6$ & $75,2 \pm 3,8$ & $85,4 \pm 2,1$ & $86,3 \pm 1,4$ & 11,26 & 0,0002 & $\mathrm{Q}^{1}$ \\
\hline CMMS & $55,8 \pm 7,0$ & $76,8 \pm 6,6$ & $86,5 \pm 3,5$ & $87,5 \pm 2,5$ & 8,02 & 0,002 & $\mathrm{Q}^{2}$ \\
\hline CMPB & $63,2 \pm 7,5$ & $71,7 \pm 7,3$ & $79,3 \pm 3,4$ & $79,5 \pm 2,9$ & 10,25 & 0,002 & $\mathrm{Q}^{3}$ \\
\hline EMA & $2478 \pm 228$ & $3069 \pm 156$ & $3489 \pm 84$ & $3523 \pm 56$ & 11,51 & 0,0002 & $\mathrm{Q}^{4}$ \\
\hline EMAn & $2096 \pm 223$ & $2757 \pm 157$ & $3161 \pm 84$ & $3226 \pm 56$ & 12,69 & $<0,0001$ & $Q^{5}$ \\
\hline SQD* & $6,28 \times 10^{6}$ & $1,46 \times 10^{6}$ & $3,88 \times 10^{5}$ & $1,96 \times 10^{5}$ & - & - & - \\
\hline
\end{tabular}

$\mathrm{Q}^{1}-\mathrm{Y}=38,085+2,5752 \mathrm{x}-0,0341 \mathrm{x}^{2}\left(\mathrm{R}^{2}=0,99\right) ; \mathrm{Q}^{2}-\mathrm{Y}=25,575+3,529 \mathrm{x}-0,0496 \mathrm{x}^{2}\left(\mathrm{R}^{2}=0,99\right) ; \mathrm{Q}^{3}-\mathrm{Y}=32,255+$ $2,862 \mathrm{x}-0,0423 \mathrm{x}^{2}\left(\mathrm{R}^{2}=0,99\right) ; \mathrm{Q}^{4}-\mathrm{Y}=1554,8+105,18 \mathrm{x}-1,3925 \mathrm{x}^{2}\left(\mathrm{R}^{2}=0,62\right) ; \mathrm{Q}^{5}-\mathrm{Y}=1116,5+112,44 \mathrm{x}-1,49 \mathrm{x}^{2}$ $\left(\mathrm{R}^{2}=0,66\right)$; SQD: soma dos quadrados dos desvios do consumo de EMAn; CV: coeficiente de variação.

Mesmo comportamento foi encontrado para coeficientes de metabolizabilidade da energia bruta (CMEB). Observa-se que houve diferença significativa entre os níveis de substituição e, à medida que a MOL era adicionada, o seu aproveitamento energético também foi incrementado, chegando a $86,27 \%$ no nível de $40 \%$. Na derivação da equação de regressão, o nível que resultou em melhor aproveitamento energético foi o de $37,7 \%$.

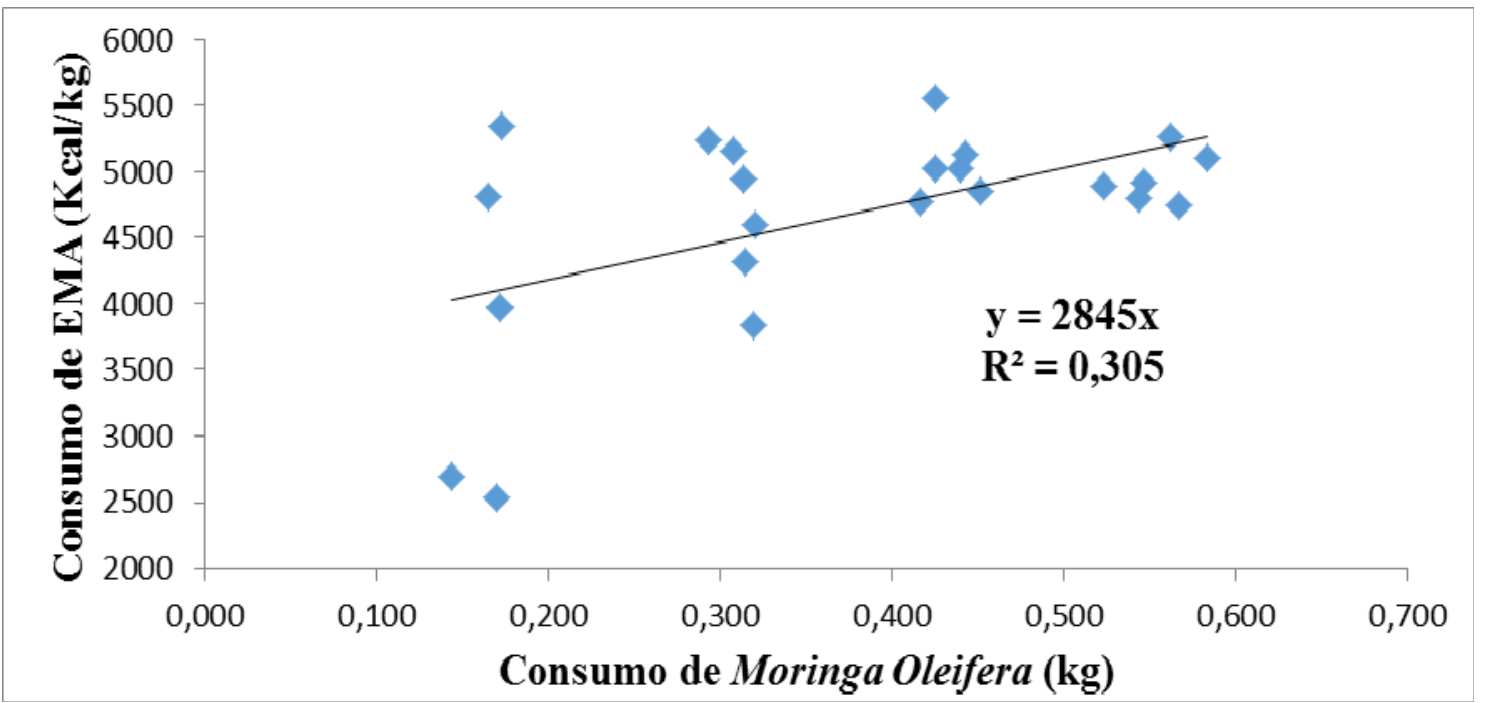

Figura 1. Valor estimado da EMAn para frangos de corte da MOL.

Para os coeficientes de metabolizabilidade aparente da matéria seca (CMAMS) e da proteína bruta (CMAPB), também houve diferença significativa. $\mathrm{O}$ efeito sobre a metabolização da MS e da PB foi de aumento à medida que eram incrementados os níveis de moringa na ração. No desdobramento das equações de regressão, para essas variáveis, os 
níveis de substituição de moringa que proporcionaram o melhor aproveitamento foram de $36,6 \%$ para $\mathrm{MS}$ e de 33,8\% para $\mathrm{PB}$.

Observando-se os gráficos da Fig. 2, pode-se notar que os aumentos dos níveis de substituição melhoraram a determinação dos valores de aproveitamento da matéria seca e da proteína bruta, fato que pode ser comprovado pela dispersão dos pontos sobre a reta. Analisando-se os gráficos, pode-se concluir que níveis acima de $30 \%$ são mais precisos na determinação dessas variáveis.

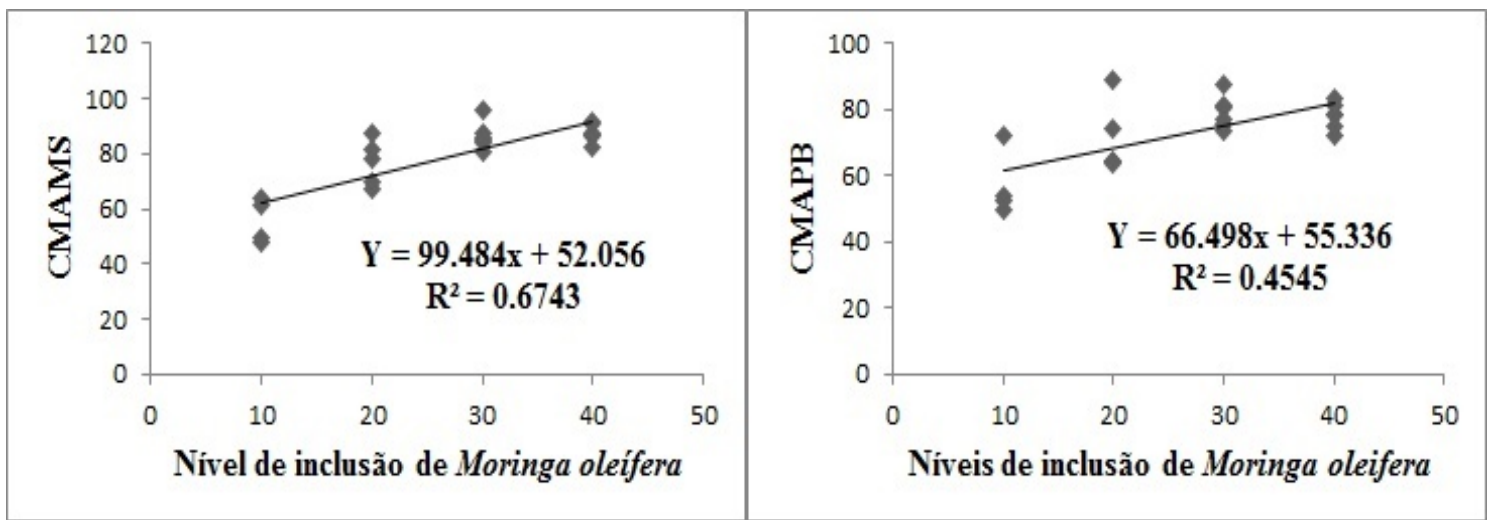

Figura 2. Coeficiente de metabolizabilidade aparente da matéria seca e proteína bruta.

\section{DISCUSSÃO}

O valor nutricional de qualquer forrageira está intimamente relacionado às suas composições histológica e bromatológica, estado vegetativo, condições edafoclimáticas em que a planta foi cultivada e fração utilizada (caule, folhas ou caule + folhas) para a fabricação do farelo (Brito et al., 1999; Carvalho e Pires, 2008; Arruda et al., 2010).

A composição química de Moringa oleifera é muito variável entre os trabalhos. Valores de matéria seca entre $86 \%$ e $92 \%$ (Zanu et al., 2012) são relatados. Quanto ao teor de proteína bruta, a variação é ainda maior; segundo Moura et al. (2010), para folhas de moringa, esses valores estão, em média, em torno de $25 \%$. No entanto, dependendo da idade em que a planta é cortada e das condições edafoclimáticas em que ela é cultivada, seus valores nutricionais podem variar, podendo chegar a apresentar teores de PB de até $31 \%$ em alguns casos, sendo esse valor relatado por Montayoba et al. (2011).

A composição aminoacídica da moringa utilizada nesta pesquisa ficou abaixo da determinada por Mutayoba et al. (2011). No entanto, deve-se considerar que o farelo de folhas analisado pelo referido autor apresentava teor proteico de $30,65 \%$, ao passo que o utilizado neste experimento tinha $18,31 \%$. Essa diferença levou, sem dúvida, às diferenças nas porcentagens dos aminoácidos. O farelo de folhas utilizado apresentou níveis baixos de metionina e lisina se comparado ao farelo de soja. No entanto, comparando-se o perfil aminoácídico das folhas da planta com o do farelo de trigo, ingrediente utilizado em algumas situações na formulação de ração de aves, percebe-se que essa última apresenta níveis superiores desses aminoácidos.

Pode-se observar, na Tab. 4, que o conteúdo de FDN (fibra em detergente neutro) ficou em torno de 41,99\%, estando presentes nessa fração a celulose, a hemicelulose e a lignina. Já no FDA (fibra em detergente ácido), onde se encontram, principalmente, a celulose e a lignina, a concentração determinada ficou em torno de 23,46\%. Considerando-se esse resultado, conclui-se que boa parte da fibra do da Moringa oleifera utilizada constituía-se de sua fração solúvel.

Sabe-se que a fibra solúvel, representada pela fração de hemicelulose e pectina, tem a capacidade de diminuir a taxa de passagem do alimento pelo trato gastrointestinal. Devido a essa característica, há um maior tempo de permanência do alimento em contato com as enzimas digestivas do animal, o que pode, até certo ponto, aumentar o aproveitamento dos nutrientes contidos na dieta (Johnston et al., 
2003; Montagne et al., 2003; Owusu-Asiedu et al., 2006).

A moringa em estudo apresentou menor teor de EB (4526kcal $/ \mathrm{kg})$ do que os encontrados por Makkar e Becker (1997). Esses autores, ao estudarem diferentes partes da planta da moringa, encontraram valores de $4625 \mathrm{kcal} / \mathrm{kg}$ para suas folhas. No entanto, esse valor ficou acima dos valores determinados por Gadzirayi et al. (2012) de $4469 \mathrm{kcal} / \mathrm{kg}$.

Essas diferenças nos valores de EB referem-se às variações na composição química, principalmente a $\mathrm{PB}$, o EE e a fibra do farelo de folhas de moringa utilizados nos respectivos experimentos. Gadzirayi et al. (2012), por exemplo, com material contendo porcentagem de proteína bruta $(22,5 \%)$ maior que a moringa utilizada neste experimento, apresentaram valor de EE inferior $(5,4 \%)$. Sabe-se que os componentes lipídicos, quando metabolizados, fornecem a maior quantidade de energia bruta quando comparados a carboidratos e proteínas.

Com o aumento dos níveis de inclusão de moringa, menores eram as diferenças entre os valores de EMA e EMAn (Tab. 3). Na maioria das situações, é necessário corrigir todos os valores de energia encontrados pelo balanço de nitrogênio, visto que é praticamente impossível assegurar que todas as aves nos tratamentos apresentem a mesma taxa de crescimento. Nas aves em crescimento, como as utilizadas neste experimento, a proteína retida no corpo não é catabolizada até o produtos finais de excreção, o ácido úrico; este, consequentemente, não contribui para a energia das excretas. A correção pelo balanço de nitrogênio tem como objetivo padronizar os valores de EMA em diferentes condições (Sakomura e Rostagno, 2007).

Ayssiwede et al. (2011) utilizaram equações de regressão descritas por Sauvant et al. (2004) para a determinação da EM da moringa; estas levavam em consideração o conteúdo de proteína bruta, fibra bruta, extrato etéreo e cinzas. $\mathrm{O}$ valor de energia determinado por esses autores ficou em torno de $2888 \mathrm{kcal} / \mathrm{kg}$. Já Kaijage et al. (2015) estimaram uma energia metabolizável de $1879 \mathrm{kcal} / \mathrm{kg}$ das folhas de Moringa oleifera utilizando equações de predição.
Olugbemi et al. (2010), ao trabalharem com frangos de corte, relaram valores de $2978 \mathrm{kcal} / \mathrm{kg}$, valor esse próximo ao determinado no nível de substituição de 20\%. Já Nkakwana et al. (2014) citam valores de EMA de $2725 \mathrm{kcal}$.

Penz Jr. et al. (1999) relatam que alimentos que têm um alto teor de fibra em sua composição apresentam, consequentemente, menores coeficientes de metabolizabilidade da energia bruta, ou seja, apresentam menor aproveitamento energético devido à menor digestibilidade da fibra no trato digestório das aves.

O processamento das folhas, que foram moídas em partículas muito finas, formando literalmente um farelo fino, pode ter melhorado o aproveitamento do material, visto que o menor tamanho de partículas resulta em maior superfície de contato do material com as enzimas dos microrganismos presentes no ceco e consequente maior fermentação, assim como o rompimento da camada de epiderme das células vegetais, esta se caracterizando em uma barreira para a aderência e penetração dos microrganismos (Penz e Maiorka, 1996; Carvalho e Pires, 2008).

Mateos et al. (2012) relatam que, dependendo dos níveis de inclusão e do tipo da fibra utilizada, a digestibilidade dos nutrientes pode ser melhorada pelo efeito que esse componente tem sobre o ventrículo (moela) dos animais, assim como seus efeitos sobre a secreção de enzimas digestivas.

Alguns trabalhos sugerem que a inclusão de fibra na dieta melhora o desenvolvimento da moela, visto que sua presença nesse órgão eleva sua motilidade, influenciando, também, os movimentos de todo o trato digestivo. Tais efeitos proporcionam aumento na liberação de coliscistoquinina (CCK), hormônio importante na liberação de enzimas digestivas pelo pâncreas. $\mathrm{O}$ aumento da motilidade também melhora a mistura do alimento com essas enzimas (Svihus et al., 2004; Hetland et al., 2005).

Existe uma estreita relação entre o ventrículo e o proventrículo. O aumento da atividade da moela resultaria em incremento dos movimentos antiperistálticos do trato gastrointestinal, o que acarretaria refluxo de material para $o$ proventrículo e, consequentemente, aumento na 
liberação de $\mathrm{HCl}$ e pepsinogênio, bem como melhora na digestão de proteínas (JiménezMoreno et al., 2009). Com isso, os efeitos combinados de aumento da moagem do alimento no ventrículo, somado com os movimentos antiperistálticos, resultariam em melhora da mistura da digesta com as enzimas digestivas, o que pode, em parte, explicar os aumentos gradativos nos valores de EMA encontrados no presente estudo, visto que se conseguiu melhorar a digestibilidade dos nutrientes.

Outra explicação possível seria o efeito do desaparecimento de parte do alimento no trato digestivo que foi fermentada pela microbiota no ceco e consequente produção de ácidos graxos de cadeia curta e gases. Esse material foi utilizado pelas bactérias cecais e a energia perdida nesse processo pode ser subtraída da energia digestível para que se possam fazer os cálculos de energia metabolizável (Warpechowski, 2005).

Tais fatos podem explicar o incremento dos valores de EMA e EMAn observado com o aumento dos níveis de inclusão, assim como a melhora gradativa dos coeficientes de metabolizabilidade aparente da MS, PB e EB. Para o primeiro caso, esses aumentos são devido ao melhor aproveitamento do material graças ao seu efeito sobre o trato digestório, melhorando a digestibilidade dos nutrientes da ração. $\mathrm{O}$ desaparecimento da MS e da energia pode ter sido devido à fermentação microbiana do material que chegou ao ceco.

\section{CONCLUSÕES}

A Moringa oleifera usada no estudo apresentou composição química variável quando comparada com a literatura. Os valores estimados de EMA, EMAn, CMAPB, CMAMS, CMAPB foram $3140 \mathrm{kcal} / \mathrm{kg}, \quad 2845 \mathrm{kcal} / \mathrm{kg}, 76,92 \%, 76,63 \%$ e $73,42 \%$, respectivamente. Percebe-se, pelos resultados obtidos, que a MOL apresenta grande potencial de ser utilizada na alimentação de frangos de corte, visto que possui a capacidade de melhorar o aproveitamento dos nutrientes.

\section{REFERÊNCIAS}

ARRUDA, A.M.V.; FILGUEIRA, T.M.B.; FERNANDES, R.T.V et al. Avaliação nutricional de feno de mata pasto com aves caipiras. Acta Vet. Bras., v.4, p.193-198, 2010.
AYSSIWEDE, J.C.; ZANMENOU, Y.; ISSA, M.B. et al. Nutrient composition of some unconventional and local feed resources available in Senegal and recoverable in indigenous chickens or animal feeding. Pak. J. Nut., v.10, p.707-717, 2011.

BRITO, C.J.F.A.; RODELLA, R.A.; DESCHAMPS, F.C.; ALQUINI, Y. Anatomia quantitativa e degradação in vitro de tecidos em cultivares de capim elefante (Pennisetum purpureum Schumach.). Rev. Bras. Zootec., v.28, p.223-229, 1999.

CARVALHO, G.G.P.; PIRES, A.J.V. Organização dos tecidos de plantas forrageiras e suas implicações para os ruminantes. Arch. Zootec., v.57, p.13-28, 2008.

GADZIRAYI, C.T.; MASSAMHA, B.; MUPANGWA, J.F.; WASHAYA, S. Performace os broiler chickens fedo $\mathrm{n}$ moringa oleifera leaf meal as a protein supplement to soyabean meal. Int. J. Poult. Sci., v.11, p.5-10, 2012.

HETLAND, H.; SVIHUS, B.; CHOCT, M. Role of insoluble fiber on gizzard activity in layers. J. Appl. Poult. Res., v.14, p.38-46, 2005.

JIMÉNEZ-MORENO, E.; GONZÁLEZALVARADO, J.M.; LÁZARO, R.; MATEOS, G.G. Effects of type of cereal, heat processing of the cereal, and fiber inclusion in the diet on gizzard ph and nutrient utilization in broilers at different ages. Poult. Sci., v.88, p.1925-1933, 2009.

JOHNSTON, L.J.; NOLL, S.; RENTERIA, A.; SHURSON, J. Feeding by-products high in concentration of fiber to non ruminants. In: NATIONAL SYMPOSIUM ON ALTERNATIVE FEEDS FOR LIVESTOCK AND POULTRY, 3., 2003, Kansas. Proceedings... Kansas City: [s.n.], 2003. p.169-186 (Abstract).

KAIJAGE, J.T.; MUTAYOBA, S.K.; KATULE, A. Moringa oleifera leaf meal and molasses as additives in grain sorghum based diets for layer chickens. Livest. Res. Rural Dev., v.27, p.1-5, 2015.

MAKKAR, H.P.S.; BECKER, K. Nutrients and antiquality factors in different morpholofical parts of the moringa oleifera tree. J. Agric. Sci., v.128, p.311$322,1997$.

MATEOS, G.G.; JIMÉNEZ-MORENO, E.; SERRANO, M.P.; LÁZARO, R.P. Poultry response to high levels of dietary fiber sources varying in physical and chemical characteristics. J. Appl. Poult. Res., v.21, p.156-174, 2012.

MATTERSON, L.D. et al. The metabolizable energy of feed ingredients for chickens. Res. Rep., v.7, p.3-11, 1965. 
MONTAGNE, L.; PLUSKE, J.R.; HAMPSON, D.J. A review of interactions between dietary fibre and the intestinal mucosa, and their consequences on digestive health in young non-ruminant animals. Anim. Feed. Sci. Technol., v.108, p.95-117, 2003.

MOURA, A.S.; SOUZA, A.L.G.; OLIVEIRA JUNIOR, A.M. et al. Caracterização físico-química da folha, flor e vagem de Moringa (Moringa olifera Lamarck). In: ENCONTRO NACIONAL DE MORINGA, 2010, Aracaju. Anais... Sergipe: [s.n.], 2010. (Resumo).

MOYO, B.; MASIKA, P.J.; HUGO, A.; MUCHENJE, $\mathrm{V}$. Nutricional characterization of moringa oleifera (Moringa oleifera lam) leaves. Afr. J. Biotechnol., v.10, p.12925-12933, 2011.

MUTAYOBA, S.K.; DIERENFELD, E.; MERCEDES, V.A. et al. Determination of chemical composition and ant-nutritive components for Tazanian locally available poultry feed ingredients. Int. J. Poult. Sci., v.10, p.350-357, 2011.

NKAKWANA, T.T.; MUCHENJE, V.; PIETERSE, E. et al. Effect on Moringa oleifera leaf meal on growth performace, apparent digestibility, digestive organ size and carcass yield in broiler chickens. Livest. Sci. v.161, p.139-146, 2014.

OLUGBEMI, T.S.; MUTAYOBA, S.K.; LEKULE, F.P. Effect of Moringa (Moringa oleifera) inclusion in cassava based diets fed to broiler chickens. Int. J. Poult. Sci., v.9, p.363-367, 2010.

OWUSU-ASIEDU, A.; PATIENCE, J.F.; LAARFELD, B. et al. Effects of guar gum and cellulose on digesta passage rate, ileal microbial populations, energy and protein digestibility, and performance of grower pigs. J. Anim. Sci., v.84, p.843$852,2006$.

PASQUETTI, T.J.; FURLAN, A.C.; TON, A.P.S. et al. Semi-purified glycerin in the meat quails feeding. Semina, v.35, p.3377-3392, 2014.

PENS, J.R.; MAIORKA, A. Uso de rações com diferentes graus de granulometria para frangos de conte. Curitiba. In: CONFERÊNCIA APINCO'96 DE CIÊNCIA E TECNOLOGIA AVÍCOLAS, 1996 , Curitiba. Anais... Curitiba: APINCO, 1996. p.33-50.
PENZ J.R.; KESSLER, A.M.; BRUGALLI, I. Novos conceitos de energia para aves. In: SIMPÓSIO INTERNACIONAL SOBRE NUTRIÇÃO DE AVES, 1999, Campinas. Anais... Campinas: Fundação Apinco de Ciência e Tecnologia Avícolas, 1999. p.1-24.

RIBEIRO, A.M.L.; HENN, J.D.; SILVA, G.L. Alimentos alternativos para suínos em crescimento e terminação. Acta Sci., Vet. v.38, p.61-71, 2010.

ROSTAGNO, H.S. et al. 3.ed. Tabelas brasileiras para aves e suínos: composição dos alimentos e exigências nutricionais. Viçosa: UFV, 2011. 252p.

SAKOMURA, N.K.; ROSTAGNO, H.S. Métodos de pesquisa em nutrição de monogástricos. Jaboticabal: FUNEP, 2007. 283p.

SAUVANT, D., PEREZ, J.M. \& TRAN, G., Table de composition et de valeur nutritive des matières premières destinées aux animaux d'élevage: Porcs, volailles, bovins, ovins, caprins, lapins, chevaux, poissons. 2è édition revue et corrigée, INRA: Paris, 2004. 301p.

SILVA, D.J.; QUEIROZ, A.C. Análise de alimentos: métodos químicos e biológicos. Viçosa: Imprensa Universitária, 2002. 235p. (Livro Texto).

SVIHUS, B.; JUVIK, E.; HETLAND, H.; KROGDAHL, A. Causes for improvement in nutritive value of broiler chicken diets with whole wheat instead of ground wheat. Br. Poult. Sci., v.45, p.55-60, 2004.

WARPECHOWSKI, M.B. Efeito do nível e fonte de fibra sobre a concentração e a utilização da energia metabolizável de dietas para frangos de corte em crescimento. 2005. 215f. Tese (Doutorado em Zootecnia) - Faculdade de Agronomia, Universidade Federal do Rio Grande do Sul, Porto Alegre, RS.

ZANU, H.K.; ASIEDU, P.; TAMPUORI, M. et al. Possibilities of using Moringa (Moringa oleifera) leaf meal as a partial substitute for fishmeal in broiler chickens diets. J. Anim. Feed Res., v.2, p.70-75, 2012. 